\section{The curious case of hemoglobin DC disease masquerading as sickle cell anemia}

\author{
Samina Hirani, ${ }^{1}$ Supriya Gupta, ${ }^{1}$ \\ Diana Veillon, ${ }^{2}$ Shajadi Patan, ${ }^{3}$ \\ Samip Master, ${ }^{3}$ Richard Mansour ${ }^{3}$ \\ ${ }^{1}$ Department of Internal Medicine and \\ ${ }^{2}$ Department of Pathology, Louisiana \\ State University Health Sciences Center, \\ Shreveport, LA; ${ }^{3}$ Division of \\ Hematology-Oncology, Feist-Weiller \\ Cancer Center, Louisiana State \\ University Health Sciences Center, \\ Shreveport, LA, USA
}

\begin{abstract}
Hemoglobin D is a relatively rare disease first reported in 1951 . We present the first reported case of Hemoglobin DC
\end{abstract} disease. This is a case of a Hemoglobinopathy with DC disease in a woman with a previous diagnosis of Hemoglobin SC disease. A 19-year-old woman presented to the Adult Hematology clinic at a tertiary care hospital in Northwest Louisiana for transition of care from Pediatric Hematology for a diagnosis of Hemoglobin SC disease diagnosed at the age 4. Historical data suggested no avascular necrosis, acute chest syndrome, and very few episodes of pain crisis. She has never taken hydroxyurea. Laboratory work showed persistently normal hemoglobin and white blood cell counts. All sickle cell preparations in the past were negative. Computerized tomography scan of the abdomen was reviewed and showed a spleen grossly normal in size and appearance. Given the incongruent clinical picture for sickle cell disease, repeat hemoglobinopathy evaluation with Capillary electrophoresis and confirmatory acid electrophoresis (to differentiate hemoglobins that co-migrate with Hemoglobin S) showed a probable double heterozygote for Hemoglobin D and $\mathrm{C}$ with suspected coexistent alpha thalassemia minor based on red blood cell indices. This case confirms the importance of the required confirmatory method to ensure a correct diagnosis since a misdiagnosis can lead to numerous adverse clinical or psychological effects for patients.

\section{Introduction}

Hemoglobin D disease is a rare condition compared to Sickle cell anemia which is a relatively common hemoglobinopathy. We present a rare case of Hemoglobin DC disease. There is some literature about Hemoglobin D disease; however, we found no cases with a DC combination. Given the rarity of the disease, prevalence is unknown. Hemoglobin D itself is phenotypically silent. ${ }^{1}$ However, Sickle cell disease has many genotypic and phenotypic variants depending on the hemoglobin variant. ${ }^{2}$ Gel electrophoresis is a commonly used method to diagnosis of Sickle cell disease, Sickle trait and other sickling hemoglobin variants. ${ }^{3,4}$ Cellulose acetate electrophoresis at $\mathrm{pH} 8.4$ is a standard method of separating hemoglobin $\mathrm{S}(\mathrm{HbS})$ from other Hemoglobin variants. However, it does not differentiate between Hemoglobin S, G, and D. Once the presence of Hemoglobin S like variant is confirmed on cellulose acetate electrophoresis, a confirmatory acid electrophoresis on citrate agar is used to separate HB S from HB D and $\mathrm{G}$ disease since they co-migrate on alkaline ph given common net negative charge. The reason to differentiate between these hemoglobinopathies is because of the marked difference in disease course and prognosis. ${ }^{5,6}$ We present a case of 19-yearold female who was misdiagnosed with $\mathrm{HB}$ $\mathrm{SC}$ disease due to inadequate diagnostic testing.

\section{Case Report}

A 19-year-old female presented for transition of care from Pediatric Hematology to Adult Hematology. She was diagnosed with Hemoglobin SC disease with coexistent $\alpha$ thalassemia at the age 4 on cellulose acetate hemoglobin electrophoresis. She reported two episodes of possible vasoocclusive pain crisis in the past, with no history of any sickle cell anemia complications including acute chest syndrome, splenic sequestration, and avascular necrosis. She denied any history of blood or exchange transfusion or frequent infections. She did not have any family members with sickle cell disease. She denied any alcohol or illicit drug use. She denied having any current sexual partner. Physical exam showed normal vital signs. Skin showed no pallor or jaundice. Remainder of the physical exam was unremarkable. Lab workup was obtained for further evaluation. Initial blood count showed microcytic picture with normal Hemoglobin and low mean corpuscular volume (MCV) and mean corpuscular hemoglobin concentration (MCHC). Retic count was 2.2\% (0.2-1.8\%). A table of the patient's complete blood counts from 2015 to 2017 is below (Table 1).
Correspondence: Samina Hirani, Department of Internal Medicine, Louisiana State University Health Sciences Centre, 1501 Kings Hwy, Shreveport, Louisiana, 71103, USA

Tel: +1-334-221-5427

E-mail: shiran@1suhsc.edu

Key words: hemoglobin D; hemoglobin DC disease; sickle-cell anemia.

Contributions: $\mathrm{SH}$ conceived the design, reviewed the medical records, interpreted data, reviewed literature and wrote the manuscript. SG reviewed the literature and wrote the manuscript. SP, RM, SM verified the work, supervised the study and critically revised the manuscript.

Conflict of interest: The authors declare no potential conflict of interest.

Funding: None.

Ethics approval and consent to participate: The study complied with guidelines for human studies.

Informed consent: Informed consent was obtained from patient.

Received for publication: 28 February 2020. Accepted for publication: 3 March 2020.

This work is licensed under a Creative Commons Attribution-NonCommercial 4.0 International License (CC BY-NC 4.0).

${ }^{C}$ Copyright: the Author(s), 2020

Licensee PAGEPress, Italy

Hematology Reports 2020; 12:8519

doi:10.4081/hr.2020.8519

A peripheral blood smear found occasional target cells but no sickle cells (Figure 1). Lactate dehydrogenase was $145 \mathrm{U} / \mathrm{L}$ (normal range 81- $234 \mathrm{U} / 1$ ). A comprehensive metabolic panel showed sodium of 139 $\mathrm{mmol} / \mathrm{L}$ (reference value $136-145 \mathrm{mmol} / \mathrm{L}$ ) and potassium of $3.9 \mathrm{mmol} / \mathrm{L}$ (3.5$5.1 \mathrm{mmol} / \mathrm{L}$ ) with normal renal function. Other significant labs on presentation included alanine aminotransferase (ALT) of $35 \mathrm{U} / \mathrm{L} \quad(12-78 \quad \mathrm{U} / \mathrm{L}), \quad$ aspartate aminotransferase (AST) of 18U/L (15-37 $\mathrm{U} / \mathrm{L}$ ), alkaline phosphatase (ALP) of $73 \mathrm{U} / \mathrm{L}$ (45-117 U/L), and total bilirubin of 0.4 $\mathrm{mg} / \mathrm{dL}(0.2-1.0 \mathrm{mg} / \mathrm{dL})$. Stool for occult blood was negative. Chest X-ray showed no acute cardiopulmonary abnormality. Computerized tomography scan of the abdomen and pelvis with intravenous contrast was performed and showed an intact spleen. In our patient, the lack of complications associated with sickle cell 
disease such as acute chest syndrome and pain crisis, presence of intact spleen, and normal hemoglobin was what made the original diagnosis of sickle cell anemia questionable. Given the high discrepancy in lab values compared to other sickle cell disease patients, a hemoglobinopathy evaluation was performed. The result showed Hemoglobin DC disease rather than diagnosis of Hemoglobin SC disease (Figures 2 and 3). Sickle cell disease is associated with significant morbidity and mortality early in life. An incorrect diagnosis can result in significant psychological effects that can be avoided by making the correct diagnosis prior to psychological priming of a patient. This case highlights the need for complete hemoglobinopathy evaluation for correct diagnosis.

\section{Discussion}

The first reported case of Hemoglobin D disease was reported in 1951 by Itano et al. ${ }^{7}$ Since then, it remains poorly studied compared to Hemoglobin S, C and Beta thalassemia. ${ }^{8}$ It has been popularly reported as Hemoglobin D Punjab (given high prevalence in the Punjab region of Northwestern Indian) and Hemoglobin D Los Angeles (as this was first studied in Los Angeles by Itano). ${ }^{7,8}$ Hemoglobin D disease usually does not have a specific phenotypic presentation. The first reported case from Punjab was an asymptomatic male with an incidental diagnosis of hemoglobinopathy. ${ }^{9}$ Both Hemoglobin D trait and Hemoglobin DD disease are typically clinically and hematologically silent or may present with mild hemolytic anemia. As a result, these patients do not seek medical attention. ${ }^{8}$

However, Hemoglobin D acquires clinical significance when it occurs in combination with either $\beta$ thalassemia or Hemoglobin S. ${ }^{10}$ Sickle cell disease has many variants of which Hemoglobin SS disease compromises $60 \%$ cases in the United States. ${ }^{2}$ It is important to note there is not much data on the prevalence of other hemoglobinopathies. The most common clinically seen manifestations of sickle cell disease include anemia, vaso-occlusive events, splenic sequestration, and acute chest syndrome. ${ }^{11} \quad$ Other life-threatening complications include bacterial sepsis, stroke, and chronic organ damage including cerebral infarction, end stage renal disease, sickle chronic lung disease, leg ulcers and osteonecrosis. $^{12-14}$ It is important to differentiate these hemoglobinopathies since there is a marked difference in disease course and prognosis. ${ }^{5,6}$ Given the clinical risks,

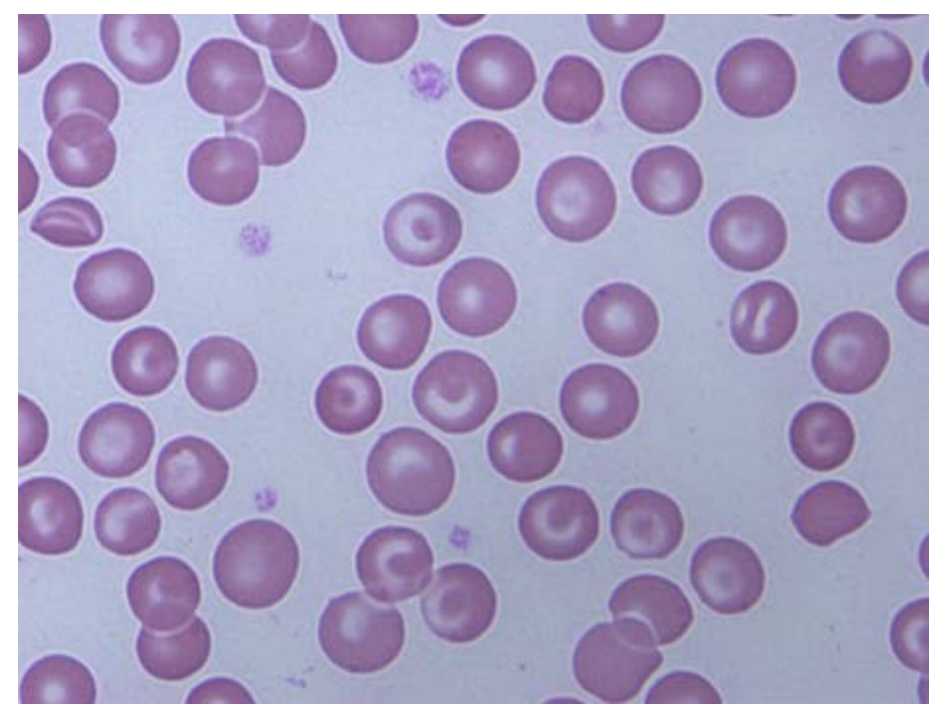

Figure 1. This the microscopic view of peripheral smear. Target cells seen. No sickle RBC identified.

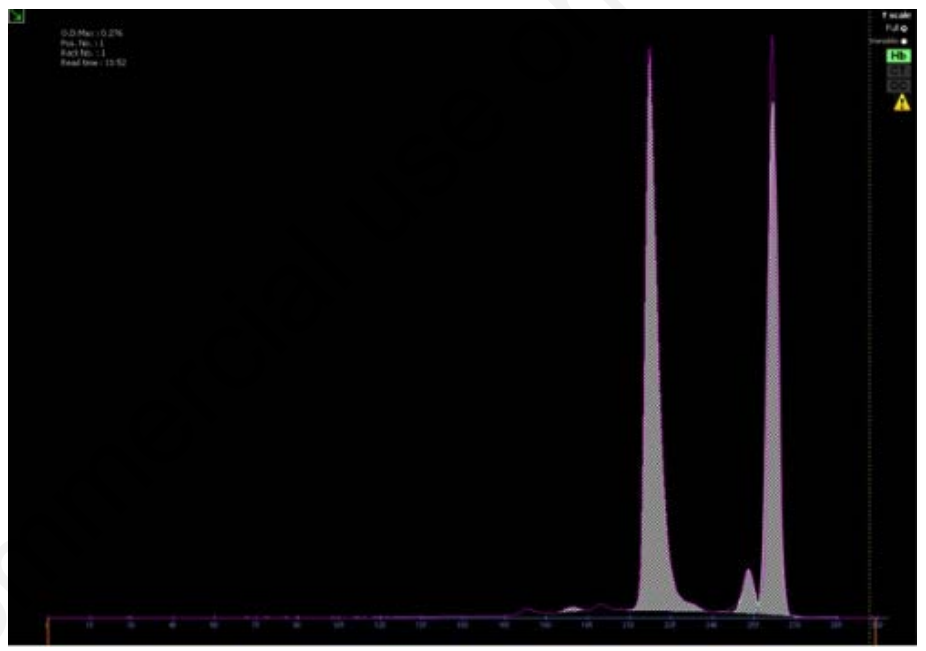

Figure 2. Capillary zone electrophoresis with two predominant peaks in HB D and HB C zone.

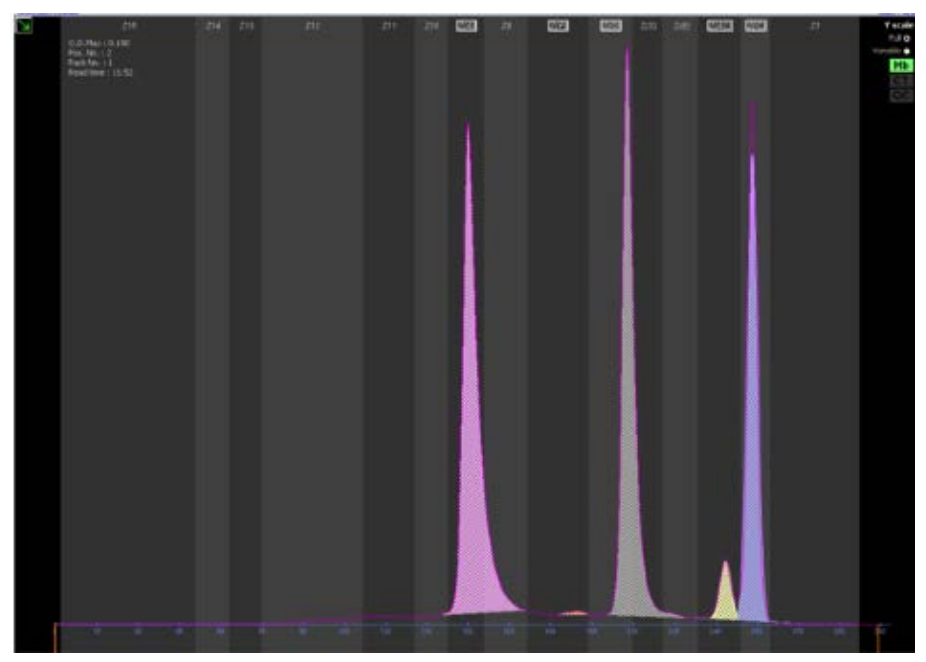

Figure 3. Capillary zone electrophoresis adjustment (addition of normal hemoglobin A allows identification of abnormal peaks). 
Table 1. A table of the patient's complete blood count from 2015 to 2017.

\begin{tabular}{lccc} 
Component (Latest Ref Range \& Units) & $3 / 3 / 2017$ & $8 / 4 / 2016$ & $2 / 19 / 2015$ \\
WBC (4.5-12.5 K/uL) & 8.14 & $17.25(\mathrm{H})$ & 8.00 \\
RBC (4.1-5.1 M/uL) & $5.84(\mathrm{H})$ & $5.71(\mathrm{H})$ & $5.66(\mathrm{H})$ \\
\hline Hemoglobin (12.0-16.0 G/dL) & 13.4 & 13.2 & 13.3 \\
Hematocrit (36-46\%) & 39.0 & 37.4 & 40.3 \\
\hline MCV (78-98 fL) & $66.8(\mathrm{~L})$ & $65.5(\mathrm{~L})$ & $71.3(\mathrm{~L})$ \\
MCH (25-33 pg) & $23.0(\mathrm{~L})$ & $23.2(\mathrm{~L})$ & $23.5(\mathrm{~L})$ \\
\hline MCHC (31-37 G/dL) & 34.4 & 35.3 & 32.9 \\
RDW (12.3-17.0 \%) & 14.8 & 15.1 & 14.4 \\
\hline Platelet (159-386 K/uL) & 218 & 209 & 263 \\
MPV (7.5-11.2 fL) & 10.1 & 9.2 & 8.2 \\
\hline
\end{tabular}

Ref: Reference,(H): High, (L): Low, K/uL: thousands per cubic milliliter, M/uL: million per microliter, G/dL: Gram/decilitre, fL: femtoliters, pg: picograms.

high mortality, and psychological effects of sickle cell disease, it is important to make the correct diagnosis.

Gel electrophoresis is one of the most commonly used and heavily relied upon tests for diagnosis of sickle cell disease vs sickle cell trait. ${ }^{3,4}$ Cellulose acetate agar runs at an alkaline $\mathrm{pH} 8.4$ is often one the first tests used by in the lab given the ease of handling and minimal preparative work. Alternatively, labs can use other methods such as capillary electrophoresis to separate hemoglobin variants, a semi-automated method which is used in our laboratory. Since both methods can't be used to confirm hemoglobins that co-migrate or co-ellute on screening, a confirmatory method must be used to accurate separate hemoglobins such as hemoglobin S from hemoglobins D and G. Therefore, the diagnosis is confirmed, often by acidic electrophoresis ( $\mathrm{pH} 6.0$ to 6.2 ) with citric agar to differentiate the hemoglobin variants. ${ }^{3-5}$ At this $\mathrm{pH}$, hemoglobin varieties that co-migrate on alkaline $\mathrm{pH}$ can be easily delineated. This method is commonly used to diagnose sickle cell disease at birth when there is a high concentration of hemoglobin F. ${ }^{15}$ In our patient, Globin chain analysis will be used for confirmation. Other diagnostic tests used include separation of different hemoglobins according to their isoelectric point by isoelectric focusing (IEF), High Performance Liquid Chromatography (HPLC) and Reversed Phase High performance liquid chromatography HPLC. ${ }^{16-18}$ In difficult cases, methods such as structural characterization of the hemoglobin polypeptide chain are used when initial tests are inconclusive. ${ }^{15,19,20}$

\section{Conclusions}

The goal is to emphasize the requirement for confirmatory tests when a diagnosis of Hemoglobin $\mathrm{S}$ disease is made to differentiate it from other hemoglobinopathies such as Hemoglobin D disease since the clinical presentation, management, course of disease and complications differ significantly. Also, complete hemoglobinopathy evaluation is important if the clinical picture is inconsistent with the previous diagnosis as occurred in our patient. Given the high prevalence of Hemoglobin S disease, it is possible that many patients with Hemoglobin D or G variants remain undiagnosed or misdiagnosed as Hemoglobin S disease. Hence, we suggest dual electrophoresis diagnosis for every patient with a preliminary diagnosis of Hemoglobin S disease. Once the presence of Hemoglobin $\mathrm{S}$ is confirmed on cellulose acetate electrophoresis it should be run on citrate agar to separate Hemoglobin S from D and G. The reason for the need for differentiation of these hemoglobinopathy is marked difference in disease course and prognosis. ${ }^{5,6}$

\section{References}

1. Shanthala Devi AM, Rameshkumar K, Sitalakshmi S. Hb D: A Not So Rare Hemoglobinopathy. Indian J Hematol Blood Transfus 2016;32:294-8.

2. MA B.Sickle Cell Disease. In: Adam MP, AH, Pagon RA, et al, eds. GeneReviews ${ }^{\circledR}$. Seattle (WA): University of Washington, Seattle; 2003.

3. Kotila TR. Guidelines for the diagnosis of the haemoglobinopathies in Nigeria. Ann Ib Postgrad Med 2010;8:25-9.

4. Piel FB, Steinberg MH, Rees DC. Sickle Cell Disease. N Engl J Med 2017;376: 1561-73.

5. Yaswon GI, Huntsman RG, Metters JS. An assessment of techniques suitable for the diagnosis of sickle-cell disease and haemoglobin $\mathrm{C}$ disease in cord blood samples. J Clin Pathol 1970;23:533-7.

6. Platt OS, Thorington BD, Brambilla DJ, et al. Pain in sickle cell disease. Rates and risk factors. N Engl J Med 1991; 325:11-6.

7. Itano HA. A Third Abnormal Hemoglobin Associated with Hereditary Hemolytic Anemia. Proc Natl Acad Sci U S A 1951;37:775-84.

8. Torres Lde S, Okumura JV, Silva DG, Bonini-Domingos CR. Hemoglobin DPunjab: origin, distribution and laboratory diagnosis. Rev Bras Hematol Hemoter 2015;37:120-6.

9. Bird GW, Lehmann H, Mourant AE. A third example of haemoglobin D. Trans R Soc Trop Med Hyg 1955;49:399-400.

10. Pant L, Kalita D, Singh S, et al. Detection of Abnormal Hemoglobin Variants by HPLC Method: Common Problems with Suggested Solutions. Int Sch Res Notices 2014;2014:257805.

11. Morris CR. Vascular risk assessment in patients with sickle cell disease. Haematologica 2011;1:1-5.

12. Powars DR. Sickle cell anemia and major organ failure. Hemoglobin 1990;14:573-98.

13. Bunn HF. Pathogenesis and treatment of sickle cell disease. N Engl J Med 1997; 337:762-9.

14. Morris CR. Mechanisms of vasculopathy in sickle cell disease and thalassemia. Hematology Am Soc Hematol Educ Program 2008:177-85.

15. Vella F. Acid-agar gel electrophoresis of human hemoglobins. Am J Clin Pathol 1968;49:440-2.

16. Alter BP, Goff SC, Efremov GD, et al. Globin chain electrophoresis: a new approach to the determination of the $G$ gamma/A gamma ratio in fetal haemoglobin and to studies of globin synthesis. Br J Haematol 1980;44:52734.

17. Nemati H, Bahrami G, Rahimi Z. Rapid separation of human globin chains in normal and thalassemia patients by RPHPLC. Mol Biol Rep 2011;38:3213-8.

18. Wan JH, Tian PL, Luo WH, et al. Rapid determination of human globin chains using reversed-phase high-performance liquid chromatography. J Chromatogr B Analyt Technol Biomed Life Sci 2012;901:53-8.

19. Marengo-Rowe AJ. Rapid electrophoresis and quantitation of haemoglobins on cellulose acetate. J Clin Pathol 1965;18:790-2.

20. Schneider RG. Differentiation of electrophoretically similar hemoglobins - such as S, D, G, and P; or A2, C, E, and O- by electrophoresis of the globin chains. Clin Chem 1974;20:1111-5 